\title{
ON SUFFICIENT CONDITIONS FOR A POLYNOMIAL TO BE SIGN-INDEPENDENTLY HYPERBOLIC OR TO HAVE REAL SEPARATED ZEROS
}

\author{
IRINA KARPENKO AND ANNA VISHNYAKOVA
}

Abstract. The well-known Hutchinson's theorem states that if $P$ be a polynomial with positive coefficients, $P(x)=\sum_{k=0}^{n} a_{k} x^{k}$, and $\frac{a_{k-1}^{2}}{a_{k-2} a_{k}} \geqslant 4$ for $k=2,3, \ldots, n$, then all the zeros of $P$ are real. We obtain sufficient conditions for a real polynomial to be a sign-independently hyperbolic polynomial or to have real separated roots in the style of Hutchinson's theorem.

Mathematics subject classification (2010): 30C15, 26C10, 47B38.

Keywords and phrases: Hyperbolic (real-rooted) polynomial, sign-independently hyperbolic polynomial, mesh of polynomial, zero separation.

\section{REFERENCES}

[1] T. Craven and G. Csordas, Complex zero decreasing sequences, Methods Appl. Anal., 2, (1995), $420-441$.

[2] J. Forsgård, D. Novikov, B. Shapiro, A tropical analog of Descartes' rule of signs, arXiv: 1510.03257.

[3] G. H. HARdY, On the zeros of a class of integral functions, Messenger Math., 34, (1904), 97-101.

[4] G. H. Hardy, Collected Papers of G. H. Hardy, vol. IV, Oxford Clarendon Press, 1969.

[5] J. I. Hutchinson, On a remarkable class of entire functions, Trans. Amer. Math. Soc., 25, (1923), 325-332.

[6] M. Passare, J. M. Rojas, AND B. Shapiro, New multiplier sequences via discriminant amoebae, Mosc. Math. J., 631, 11 (2011), no. 3, 547-560.

[7] M. Petrovitch, Une classe remarquable de séries entiéres, Atti del IV Congresso Internationale dei Matematici, Rome, (Ser. 1), 2, (1908), 36-43. 